\title{
The Construction of Digital Campus in the Construction of Civilized Campus in Private Colleges and Universities
}

\author{
Jiequan Wang ${ }^{1}$ and Jun Wang ${ }^{2}$
}

(General Education Center of Xijing University, Xi'an Shaanxi 710123)

\begin{abstract}
The construction of humanistic campus is multidimensional. Based on the perspective of scientific development, this paper analyzes the construction of digital campus in the construction of humanistic campus in private colleges and universities. With being human-oriented as the main line, this paper analyzes the connotation, functions, significance and countermeasures of construction digital campus in the construction of humanistic campus in private colleges and universities, providing some thoughts and suggestions for the construction of digital campus in private colleges and universities in China.
\end{abstract}

Keywords: Private colleges and universities; Humanistic campus; Digital campus; Construction

\section{民办高校人文校园建设中的数字化校园建设}

\author{
王洁泉 ${ }^{1}$ 王俊 ${ }^{2}$ \\ (西京学院通识教育中心, 陕西西安 710123)
}

摘要: 人文校园建设是多维度的, 本文基于科学发展观的视角对民办高校人文校园建设中的数字化校园建设进行了分析。 本文围绕以人为本的主线，分析了民办高校人文校园建设中数字化校园建设的内涵、功能及意义、对策，以其为我国民办高 校建设中数字化校园建设提供一些思路和建议。

关键词: 民办高校; 人文校园; 数字化校园; 建设

引言

数字化校园建设是学校一项基础性、长期性和经常性的工作, 是学校人文校园建设和人才培养的重要 组成部分, 其建设水平是学校整体办学水平、学校形象和地位的重要标志。当前, 网络信息技术飞速发展, 对高等教育产生了巨大冲击, 从教育环境、教育模式到教育理念、教育目标, 都在这场冲击中发生着重大 变革。根据自身发展的需要, 顺应信息技术的发展潮流, 采用先进的信息技术来构建数字化校园, 加快信 息化建设步伐是学校占领信息制高点的一个有力的举措, 也是各个学校信息化建设提供了机遇和条件。民 办高校在人文校园建设中, 当然也要在科学发展观的指导下, 顺应潮流, 抓住机遇, 创造条件, 迎头赶上。

\section{1 民办高校人文校园建设中数字化校园建设的现状及问题}

\section{1 人文校园建设}

现代大学制度的不断完善和高校信息化建设的加快, 管理人员的知识化、信息化、网络化、专业化的 要求也逐步提高。民办高校在深入贯彻和落实科学发展观过程中, 以师生为本, 以 “热情、优质、高效” 为工作要求, 通过信息化建设, 实现信息的网络共享和, 方便快捷高效, 为更好地服务于学校的各项事业 起到了巨大的推动作用。通过数字化建设, 提升学校的人文关怀, 塑造优良校风, 激发广大教职工的主人 翁精神和创新、高效、服务、管理、育人的积极性, 形成人人讲责任、人人讲贡献、人人讲服务的良好格 局, 构建人文和谐校园。 
目前, 我国校园信息化的发展很不平衡, 出现两头贫富不均的布局。一方面, 国家支持建设的重点高 校有着充裕的资金和制度保障，建立起了先进的数字化校园; 另一方面，民办高校、高职院校和一些独立 学院的情况不容乐观。多年来, 由于我国政府对高校的财政拨款很少照顾到民办高校, 民办高校只有走自 主发展道路，自立筹集资金来发展学校各项事业，一般走的是 “硬件先行、师资后到位” 的发展路线，再 加上各民办高校发展差距较大, 导致信息资源分散, 数字化人才匮乏, 发展极不平衡, 缺乏科学的规划和 相互借鉴共享成果。这直接影响到民办高校人文关怀，影响到学校的办学层次和知名度。因此，需要对民 办高校数字化校园建设进行再认识。

\section{2 数字化校园建设的内涵}

综合韩锡斌等不同学者的观点, 数字化校园是指利用多媒体、网络技术，将学校的主要信息资源的数 字化, 并实现数字化信息管理方式和沟通传播方式, 从而形成高度信息化的人才培养环境。对其内涵可做 如下具体解释:

一是计算机的广发应用及良好的网络设施是建设数字化学习环境的前提基础。

二是数字化包括信息资源的数字化、信息管理方式的数字化和沟通传播方式的数字化等环节。

三是数字化将渗透在学校教学、科研、管理、公共服务以及学校社区服务等各个领域中，整个工作围 绕着新型人才培养模式和培养环境的探索而展开。

四是其深层意义在于构建适应信息社会要求的新的高等教育教学模式。

\section{3 民办高校人文校园建设中数字化校园建设的功能及意义}

在科学发展观指导下，民办高校数字化校园应为学校的教学、科研、管理、公共服务、学校社区、国 际交流、学生就业等各方面提供全面、切实的支持和服务。

\section{1 是营造数字化学习环境, 为学生的学习服务}

科学发展观强调在教师指导下以学生为中心的学习。在教育、教学过程中, 学生是主体, 一切教育教 学手段都是为学生的有效学习提供服务的, 让学生花最少的时间和精力, 达到特定的教育、教学目标, 从 而促进学生的学习最优化。信息社会, 随着校园数字化的建设, 正在改变着以往的学习方式。学生的学习 范围和时空也在正发生着变化。学习知识的范围从课堂、课本延伸到了各个领域、各门学科; 学习时空从 课堂延伸到课余的任何时间、空间领域。数字化环境的建设, 为学习者提供了丰富的数字化学习资源, 能 够提供学生课外学习的灵便性, 激发学生的兴趣, 帮助学生进行自主性、协作性、探究性学习, 巩固和升 华课堂知识, 有效的促进学生多样化学习方式的形成和个性化的发展, 进而有效地促进学生的认知发展和 创新能力的提高, 更好地培养学生的信息素养以及问题解决能力和创新能力, 实现教学模式的有效转变。

\section{2 优化教学环境, 为教师的教学活动服务}

教育教学过程是 “教师为主导、学生为主体” 的学习活动, 结果应达到教育教学效果最优化。传统的 课堂教学中, 教师也有许多的好的教学设计思想, 但由于资源贵乏, 使得很多的想法难以实现。而在数字 化环境下, 校园网络的教学资源库可以提供最新、最优秀的、满足教学需求的教育资源, 实现资源共享。 教师利用校园网教学资源库所提供的丰富的教育教学资源, 根据教学目标和学生的需求, 设计最好的教学 过程, 采用最好的教育教学资源和方法, 达到最好的教育教学效果。它改变了传统教学中教材、参考书唯 一的信息源的现象, 为教师的备课、教师的教学科研活动提供了便利的条件, 优化了教师的工作环境, 有 
利于深化教学改革。

\section{3 优化各种管理和公共服务资源，为师生员工的工作、生活服务}

利用信息技术实现职能信息管理的自动化，实现上下级部门之间更迅速便捷的沟通，实现不同的职能 部门之间的数据共享与协调, 提高决策的科学性和民主性, 减员增效, 形成充满活力的新型管理机制。

建立覆盖学校教学、科研、管理、生活等各个区域的宽带高速网络环境，提供面向全体师生的基本网 络服务和正版软件服务; 可以建设高质量的数字化的图书馆、档案馆、艺术馆等; 还可以在校园内建立电 子身份及其认证系统, 从而为学校高水平的教学、科研和管理等提供强有力的支撑。

适应高校后勤化改革的需要开展各种网络化服务项目, 包括电子商务、电子医疗等, 为师生员工提供 便捷、高效、集成、健康的生活和休闲娱乐服务, 形成智能型的社区服务体系。实施校园一卡通工程, 实 现网络化管理加快推进数字化校园建设步伐, 实现了管理精细化和服务快捷化, 校园一卡通集工作证、学 生证、图书证、医疗证、消费卡等功能于一体的非接触式射频卡，具有校园身份识别、商务消费及校园综 合管理等功能, 校园一卡通在食堂、超市、医院、浴室、图书馆、计算机实训中心、购电系统、自助水站 等地方均可使用。智能用电计量系统, 实现全校园用电系统监控, 既保证用电安全, 又排除浪费现象和行 为。

\section{4 深化学校的教学改革, 为转变办学模式服务}

网络的出现使学校从 “封闭” 的办学状态走向了 “开放” 状态, 加强了校内外各方面的交流与合作。 学校和学校之间借助网络互通有无, 互相借鉴, 取长补短, 实现信息资源的共享, 有利于转变 “单一”、“封 闭”式的办学模式, 推动学校教学改革的深化发展。

\section{5 建立学校与社会的联系, 为学生的就业提供切实服务}

自国家制定和颁布《民办高等教育促进法》和《民办教育促进法实施条例》以来，极大地促进了民办 高校的改革与发展, 民办高校为国家现代化建设培养出了大量的复合型实用型技能型人才, 并逐年增加, 他们成为中国劳动大军的一个重要组成部分。学生的就业事关民办高校的生存和发展, 关系到民办高校的 声誉和美誉。各民办高校充分利用网络信息的快捷性, 有力的转变了过去 “单一” 的就业模式, 不在局限 于召开现场招聘会, 可以实现学校与社会各企事业单位信息资源的对接和共享, 构建起一个适应信息社会 的大学生就业的新模式。

\section{4 民办高校如何进行数字化校园建设}

\section{1 指定相应的信息化政策规划和标准}

信息化政策和标准是数字化校园建设的重要保障。信息化政策和标准包括教育教学科研信息化的投入 规划与财务政策、数字化人才培养计划、后勤社会化社区管理服务校园通工程一体化、校企合作信息化技 术产学研转化的激励政策以及各种规范硬件、软件、服务的系列规范与要求等等。

教育教学科研信息化的规划要纳入学校的整体规划, 制定远景目标, 统一规划, 统一管理, 建立信息 化领导机构, 设置人员编制; 校园数字化建设的财政投入，开设专用资金账户，保证资金的支持; 社区服 务要适应高校后勤社会化改革, 有后勤集团负责实施校园数字化工程, 实施校园一卡通工程, 集生活、餐 饮、娱乐、洗浴等一体化。 


\section{2 坚持科学发展, 紧跟时代要求}

科学发展是数字化校园建设的重要前提。数字化校园建设, 应本着以人为本的原则, 体现人文关怀的 气息, 围绕培养新时期合格接班人的目标, 合理配置信息资源，使教学、科研、管理、公共服务等协调发 展。应加强信息系统建设, 从海量信息入库到面向对象的分布式管理、数据库技术、信息检索技术、高速 网络技术、信息安全技术等等，技术密集，几乎囊括了信息技术的最尖端所要解决的问题。

\section{3 加强基础设施建设}

基础设施建设是数字化校园建设的先决条件。基础设施建设涉及计算机设备、网络互联设备、移动终 端、多媒体设备、卫星设备等多种设备的建设与维护, 其目的是通过利用信息化设备装备当前的教育机构, 促进教育的革新与发展, 进而实现提升教育质量。因此, 在数字化校园基础设施建设中, 不但要做到需求 驱动、涉及合理、先进实用、安全可靠，还也要留有余地，便于今后扩充和更新。

\section{4 重视信息资源建设}

信息资源建设是数字化校园建设的重点。信息资源建设可被细分支持教师教学、支持学生学习以及支 持教育管理的相关资源。信息资源的数字化是优质教育资源共享的有效途径, 也是教育中开展信息技术与 课程整合的必要前提。在民办高校信息化过程中，有许多不公开表现形式的信息资源，包括基础数据库、 教育软件、数字图书馆、学科资源库、科研信息库等内在的静态信息资源, 也有在教学过程中教师与学生 互动产生的数据和信息等动态信息资源。它们具有各自的特点, 并为特定的人群服务。因此应该作为重点 建设项目。加强院校之间的交流与合作，互动有无，信息资源共享。

\section{5 强化信息化人才的培养工作}

信息化人才培养是数字化校园建设的关键。数字校园教育系统的功能能否得到充分发挥, 取决于师资 队伍和信息化岗位人员的信息化素质, 因此要采取措施对他们进行强化培训, 使他们不但能够掌握使用信 息技术的一般技能，还要懂得如何有效利用网上信息资源和开展网上教学活动; 必须重视对在职人员的培 训工作, 积极引进相关的专业人才, 以适应校园数字化建设的需要, 在校园数字化建设过程中, 配套培养 充实系统开发与维护、数字化加工与管理、标准化建设、数据库运行管理等相关人员。

\section{结语}

民办高校人文校园建设中的数字化校园建设，追求的是整个校园人文关怀下的便捷、快速、最好的集 教学、科研、工作、生活一体化信息化的服务。因此, 在数字化校园建设中, 应在科学发展观的指导下, 本着以人为本的原则, 充分利用现有资源, 从自身的实际情况出发, 拓展实现校园的时间和空间维度, 提 升传统校园的效率, 扩展传统校园的功能, 最终实现教育过程的全面信息化, 从而达到提高教学质量, 科 研和管理水平的目的。

\section{参考文献：}

[1] 郭加书, 崔然, 李岩, 张弘, 林泽东. 高校数字化校园建设的研究与实践 $[J]$. 中国高教研究. 2007 （10）：37-38.

[2]王彰平, 姜进军, 聂瑞强, 浅析数字化校园的组建 $[J]$. 中国教育信息化. 2007（03）：13-14.

[3]马恩明. 关于高校数字化校园建设的探讨 [J]. 辽宁经济管理干部学院学报. 2007 (03) 64-65.

[4]万里鹏，陈雅，郑建明. 中国高校数字化校园建设与思考 [J]. 情报科学，2004，22（3）356-362.

[5] 谢舒潇, 李招忠, 林秀曼. 多元化背景下数字化学习资源的整合与应用 [J]. 电化教育研究, 2007, （5）：34-39.

[6] 万义星 . 数字化校园和智慧校园差异性对比 [J]. 中文信息 , 2015(11). 
[7] 吴鹏 . 一种智慧校园建设方案探索 [J]. 福建电脑 ， 2014, 30 (4) : 159-161.

[8] 王媛媛. 大数据时代下数字化校园建设与民族高校辅导员职业化的探讨 [J]. 科教文汇: 上旬刊, 2015 (3):18-19.

[9] 吴明念. 大数据时代无线网络在数字化校园建设中的应用 [J]. 信息与电脑: 理论版, 2015 (16) : 105-107.

[10］李晓燕. 数字化校园建设的探索与实践 $[J]$. 信息安全与技术，2015(9):58-59.

\section{作者简介:}

王洁泉 ${ }^{1}$ (1980-), 男, 陕西西安人, 法学硕士, 西京学院通识教育中心讲师, 研究方向: 思想政治教育、高等教育。 王俊 ${ }^{2}(1982$ - ) 男, 河南南阳人, 法学硕士, 西京学院通识教育中心讲师, 研究方向: 高等教育

\section{References:}

[1] Guo Jiashu, Cui Ran, Li Yan, Zhang Hong, Lin Zedong. Research and Practice on the Construction of Digital Campus in Colleges and Universities [J]. China Higher Education Research. 2007(10): 37-38.

[2] Wang Zhangping, Jiang Jinjun, Nie Ruiqiang, On the Establishment of Digital Campus [J]. China's education information.2007 (03): 13-14.

[3] Ma Enming. Discussion on the Construction of Digital Campus in Colleges and Universities [J]. Journal of Liaoning Economic Management Cadre Institute. 2007(03)64-65.

[4] Wan Lipeng, Chen Ya, Zheng Jianming. On the Construction of Digital Campus in Chinese Universities [J]. Information Science, 2004, 22(3)356-362.

[5] Xie Shuxiao, Li Zhaozhong, Lin Xiuman. The Integration and Application of Digital Learning Resources in the Context of Pluralism [J]. E-education Research, 2007, (5): 34-39.

[6] Wan Yixing. Comparison of the Difference between Digital Campus and Intelligent Campus [J]. Chinese information, 2015(11).

[7] Wu Peng. An Exploration on the Construction Scheme of Intelligent Campus [J]. Fujian Computer, 2014, 30(4):159-161.

[8] Wang Yuanyuan. Discussion on the Construction of Digital Campus and the Professionalization of College Counselors in the Era of Big Data [J]. The Science Education Article Collects: the first half version, 2015(3):18-19.

[9] Wu Mingnian. Application of Wireless Network in Digital Campus Construction in the Era of Big Data [J]. Information and Computing: theoretical Edition, 2015(16):105-107.

[10] Li Xiaoyan. Exploration and Practice of Digital Campus Construction [J]. Information security and technology, 2015(9):58-59.

\section{Introduction to the Author:}

Wang Jiequan ${ }^{1}$ (1980-), male, born in Xi'an, Shaanxi, Master of Law, Lecturer at General Education Center of Xijing University, Research Direction: Ideological and Political Education, higher education.

Wang Jun²(1982-) male, born in Nanyang, Henan, Master of Law, Lecturer at General Education Center of Xijing University, Research Direction: higher education. 